\title{
On Stability in Multiobjective Integer Linear Programming: A Stochastic Approach
}

\author{
Walied H. Sharif and Omar M. Saad \\ Department of Mathematics and Physics, College of Arts and Sciences \\ Qatar University, Doha, P.O. Box 2713, Qatar
}

\begin{abstract}
In this study we consider a multiobjective integer linear stochastic programming problem with individual chance constraints. We assume that there is randomness in the right-hand sides of the constraints only and that the random variables are normally distributed. Some stability notions for such problem are characterized. An auxiliary problem is discussed and an algorithm as well as an illustrative example is presented.
\end{abstract}

Key words: Multiobjective integer linear programming, chance-constrained technique, stability

\section{INTRODUCTION}

Decision problems of stochastic or probabilistic optimization arise when certain coefficients of an optimization model are not fixed or known but are instead, to some extent, stochastic (or random or probabilistic) quantities.

In recent years methods of multiobjective stochastic optimization have become increasingly important in scientifically based decision-making involved in practical problems arising in economics, industry, health care, transportation, agriculture, military purposes and technology. We refer the Stochastic programming Web Site $(2002)^{[1]}$ for links to software as well as test problem collections for stochastic programming. In addition, we should point the reader to an extensive list of papers maintained by Maarten van der Vlerk at the Web Site: http://mally.eco.rug.nl /biblio/ SP list.html.

In literature there are many papers that deal with stability of solutions of stochastic multiobjective optimization problems. Among the many suggested approaches for treating stability for these problems ${ }^{[2-6]}$.

\section{PROBLEM FORMULATION AND SOLUTION CONCEPT}

The chance-constrained multiobjective integer linear programming problem with random parameters in the right-hand side of the constraints can be stated as follows:

$$
\begin{aligned}
& (\text { CHMOILP): } \quad \max F(x), \\
& \text { subject to } \\
& x \in X, \\
& \text { where } \\
& X=\left\{\begin{array}{l}
x \in R^{n} \mid P\left\{g_{i}(x)=\sum_{j=1}^{n} a_{i j} x_{j} \leq b_{i}\right\} \geq \alpha_{i}, \\
i=1,2, \ldots ., m, x_{j} \geq 0 \text { and integer, } j=1,2, . . n .
\end{array}\right\} .
\end{aligned}
$$

Here $\mathrm{x}$ is the vector of integer decision variables and $\mathrm{F}(\mathrm{x})$ is a vector of $\mathrm{k}$-linear real-valued objective functions to be maximized. Furthermore, $\mathrm{P}$ means probability and $\alpha_{\mathrm{i}}$ is a specified probability value. This means that the linear constraints may be violated some of the time and at most $100\left(1-\alpha_{i}\right) \%$ of the time. For the sake of simplicity, we assume that the random parameters $b_{i},(i=1,2, \ldots m) \quad$ is distributed normally with known means $E\left\{b_{i}\right\}$ and variances Var $\left\{b_{i}\right\}$ and independently of each other.

Definition 1: A point $x^{*} \in X$ is said to be an the problemnt solution for problem (CHMOILP) if there does not exist another $x \in X$ such that $\mathrm{F}(\mathrm{x}) \geq \mathrm{F}\left(\mathrm{x}^{*}\right)$ and $\mathrm{F}(\mathrm{x}) \neq \mathrm{F}\left(\mathrm{x}^{*}\right)$ with:

$P\left\{g_{i}\left(x^{*}\right)=\sum_{j=1}^{n} a_{i j} x_{j}^{*} \leq b_{i}\right\} \geq \alpha_{i}, i=1,2, \ldots, m$.

The basic idea in treating problem (CHMOILP) is to convert the probabilistic nature of this problem into a deterministic form. Here, the idea of employing a deterministic version will be illustrated by using the interesting technique of chance-constrained programming ${ }^{[7]}$. In this case, the set of constraints X of the problem (CHMOILP) can be rewritten in the deterministic form as:

$$
X^{\prime}=\left\{\begin{array}{l}
x \in R^{n} \mid \sum_{j=1}^{n} a_{i j} x_{j} \leq E\left\{b_{i}\right\}+K_{\alpha_{i}} \sqrt{\operatorname{Var}\left\{b_{i}\right\}}, \\
i=1,2, \ldots, m, x_{j} \geq 0 \text { and integer, } j=1,2, . . n
\end{array}\right\},
$$

where $K_{\alpha_{i}}$ is the standard normal value such that $\Phi\left(\mathrm{K}_{\alpha_{\mathrm{i}}}\right)=1-\alpha_{\mathrm{i}}$; and $\Phi(\mathrm{a})$ represents the "cumulative distribution function" of the standard normal distribution evaluated at a. Thus, the problem (CHMOILP) can be understood as the following deterministic version of a multi objective integer linear programming problem:

Corresponding Author: Walied H. Sharif, Department of Mathematics and Physics, College of Arts and Sciences, Qatar University, Doha, P.O. Box 2713, Qatar 
(MOILP):

subject to

$\mathrm{x} \in \mathrm{X}^{\prime}$

Now it can be observed, from the nature of the problem (MOILP) above, that a suitable secularization technique for treating such problems is to use the $\epsilon$ constraint method ${ }^{[8]}$. For this purpose, we consider the following integer linear programming problem with a single-objective function as:

$\mathrm{P}_{\mathrm{s}}(\varepsilon): \quad \max \mathrm{f}_{\mathrm{s}}(\mathrm{x})$,

Subject to

$$
X(\varepsilon)=\left\{x \in R^{n} \mid f_{r}(x) \geq \varepsilon_{r}, r \in K-\{s\}, x \in X^{\prime}\right\},
$$

Where $\mathrm{s} \in \mathrm{K}=\{1,2, \ldots, \mathrm{k}\}$ which can be taken arbitrary.

It should be stated here that an efficient solution $\mathrm{x}^{*}$ for the problem (CHMOILP) can be found by solving the scalar problem $\mathrm{P}_{\mathrm{s}}(\varepsilon)$ and this can be done when the minimum allowable levels $\left(\varepsilon_{1}, \varepsilon_{2}, \ldots, \varepsilon_{\mathrm{s}-1}, \varepsilon_{\mathrm{s}+1}, \ldots, \varepsilon_{\mathrm{k}}\right)$ for the (k-1) objectives $\left(f_{1}, f_{2}, \ldots, f_{s-1}, f_{s+1}, \ldots, f_{k}\right)$ are determined in the feasible region of solutions $X(\varepsilon)$.

It is clear from ${ }^{[8]}$ that a systematic variation of $\varepsilon_{i}$ 's will yield a set of efficient solutions. On the other hand, the resulting scalar problem $\mathrm{P}_{\mathrm{s}}(\varepsilon)$ can be solved easily at a certain parameter $\varepsilon=\varepsilon^{*}$ using the branch-and bound method ${ }^{[9]}$. If $x^{*} \in X\left(\varepsilon^{*}\right)$ is a unique optimal integer solution of problem $\mathrm{P}_{\mathrm{s}}\left(\varepsilon^{*}\right)$, then $\mathrm{x}^{*}$ becomes an efficient solution to the problem (CHMOILP) with a probability level $\alpha_{i}^{*}$, (i = 1, 2, . m).

\section{A PARAMETRIC STUDY ON PROBLEM (CHMOILP)}

Now, before we go further, we can rewrite problem $\mathrm{P}_{\mathrm{S}}(\varepsilon)$ in the following scalar relaxed subproblem which may occur in the branch-and-bound process as:

$P_{s}^{\prime}(\varepsilon): \quad \max f_{s}(x)$,

Subject to

$\mathrm{x} \in \mathrm{X}_{\mathrm{s}}(\varepsilon)$,

Where:

$$
X_{s}(\varepsilon)=\left\{\begin{array}{c}
x \in R^{n} \mid f_{r}(x) \geq \varepsilon_{r}, r \in K-\{s\}, \\
g_{i}(x)=\sum_{j=1}^{n} a_{i j} x_{j} \leq C_{i}, i=1,2, \ldots ., m, \\
\gamma_{j} \leq x_{j} \leq \beta_{j}, j \in J \subseteq\{1,2, . . n\} \\
\text { and } x_{j} \text { integer. }
\end{array}\right\},
$$

Where the constraint $\gamma_{\mathrm{j}} \leq \mathrm{x}_{\mathrm{j}} \leq \beta_{\mathrm{j}}, \mathrm{j} \in \mathrm{J} \subseteq\{1,2, . \mathrm{n}\}$ is an additional constraint on the decision variable $x_{j}$ and that has been added to the set of constraints of problem $\mathrm{P}_{\mathrm{s}}$ (ع) for obtaining its optimal integer solution $x^{*}$ by the branch-and-bound algorithm ${ }^{[9]}$.

In addition, it is supposed that:
$\mathrm{C}_{\mathrm{i}}=\mathrm{E}\left\{\mathrm{b}_{\mathrm{i}}\right\}+\mathrm{K}_{\alpha_{\mathrm{i}}} \sqrt{\operatorname{Var}\left\{\mathrm{b}_{\mathrm{i}}\right\}},(\mathrm{i}=1,2, \ldots \mathrm{m})$.

In what follows, definitions of some basic stability notions are given for the relaxed problem $\mathrm{P}_{\mathrm{s}}^{\prime}(\varepsilon)$ above. We shall be essentially concerned with three basic notions: the set of feasible parameters; the solvability set and the stability set of the first kind (SSK1). The qualitative and quantitative analysis of these notions has been introduced in details by Osman ${ }^{[10,11]}$ for different classes of parametric optimization problems. Moreover, stability results for such problems have been derived.

The feasibility condition for problem $P_{s}^{\prime}(\varepsilon)$ is given in the following.

The Set of Feasible Parameters:

Definition 2: The set of feasible parameters of problem $P_{s}^{\prime}(\varepsilon)$, which is denoted by $A$, is defined by:

$\mathrm{A}=\left\{\varepsilon \in \mathrm{R}^{\mathrm{k}-1} \mid \mathrm{X}_{\mathrm{s}}(\varepsilon) \neq \Phi\right\}$.

\section{The Solvability Set:}

Definition 3: The solvability set of problem $\mathrm{P}_{\mathrm{s}}^{\prime}(\varepsilon)$, which is denoted by $\mathrm{B}$, is defined by:

$$
\mathrm{B}=\left\{\varepsilon \in \mathrm{A} \mid \text { Problem }_{\mathrm{s}}(\varepsilon) \text { has an optimal integer solution }\right\} .
$$

The stability sets of the first kind:

Definition 4: Suppose that $\varepsilon^{*} \in \mathrm{B}$ with a corresponding optimal integer solution $x^{*}$, then the stability set of the first kind of problem $\mathrm{P}_{\mathrm{s}}^{\prime}(\varepsilon)$ corresponding to $\mathrm{x}^{*}$, which is denoted by $S\left(x^{*}\right)$, is defined by:

$\mathrm{S}\left(\mathrm{x}^{*}\right)=\left\{\varepsilon \in \mathrm{B} \mid \begin{array}{l}\mathrm{x}^{*} \text { remains optimal integer } \\ \text { solution of problem } \mathrm{P}_{\mathrm{s}}^{\prime}(\varepsilon)\end{array}\right\}$.

Utilization of the Kuhn-Tucker Necessary Optimality Conditions for $\mathbf{P}_{\mathbf{s}}{ }^{\prime}(\boldsymbol{\varepsilon})$ : Now, given an optimal point $\mathrm{x}^{*}$, which may be found as described earlier, the question is: For what values of the vector $\varepsilon$ the Kuhn-Tucker conditions for the subproblem $\mathrm{P}_{\mathrm{s}}{ }^{\prime}(\varepsilon)$ are satisfied?

In the following, the Kuhn-Tucker necessary optimality conditions corresponding to problem $\mathrm{P}_{\mathrm{s}}^{\prime}(\varepsilon)$ will have the form:

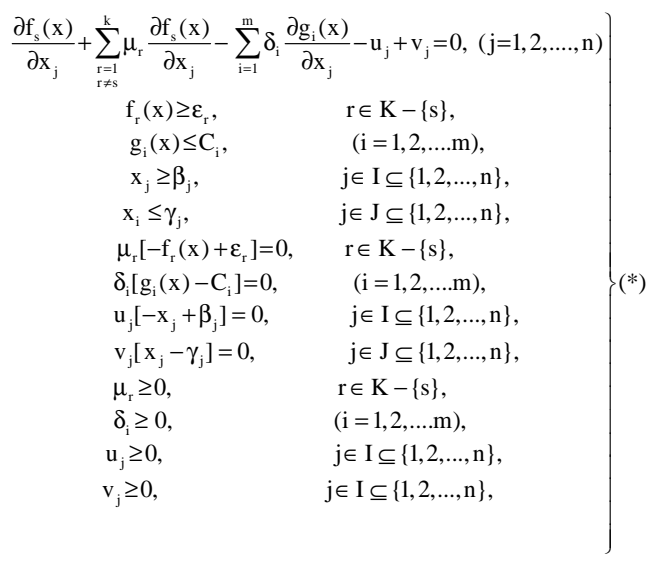


Where $\mathrm{I} \cup \mathrm{J} \subseteq\{1,2, \ldots \mathrm{n}\}, \mathrm{I} \cap \mathrm{J}=\Phi$ and all the relations of system $(*)$ above are evaluated at the optimal integer solution $x^{*}$. The variables $\mu_{\mathrm{r}}, \delta_{\mathrm{i}}, \mathrm{u}_{\mathrm{j}}, \mathrm{v}_{\mathrm{j}}$ are the longranging multipliers.

The first and last four relations of the system $(*)$ above represent a Polytope in $\mu \delta$ uv -space for which its vertices can be determined using any algorithm based upon the simplex method ${ }^{[12]}$. According to whether any of the variables $\mu_{\mathrm{r}}, \mathrm{r} \in \mathrm{K}-\{\mathrm{s}\}, \delta_{\mathrm{i}},(\mathrm{i}=1,2, \ldots$ $m), u_{j},(j \in I)$ and $v_{j},(j \in J)$ is zero or positive, then the set of parameters $\varepsilon$ 's for which the Kuhn-Tucker necessary optimality conditions are utilized will be determined. This set is denoted by $\mathrm{T}\left(\mathrm{x}^{*}\right)$.

Determination of the Set $\mathbf{T}\left(\mathbf{x}^{*}\right)$ : Now, we propose an algorithm in a series of steps to find the set of possible $\varepsilon$ which will be denoted by $\mathrm{T}\left(\mathrm{x}^{*}\right)$. For the set $\mathrm{T}\left(\mathrm{x}^{*}\right)$, the point $x^{*}$ remains efficient for all values of the vector $\varepsilon$. Clearly, $\mathrm{T}\left(\mathrm{x}^{*}\right) \subseteq \mathrm{S}\left(\mathrm{x}^{*}\right)$

The suggested algorithm can be summarized in the following manner:

Step 1: Determine the means $E\left\{b_{i}\right\}$ and $\operatorname{Var}\left\{b_{i}\right\}(i=1$, $2, \ldots \mathrm{m})$.

Step 2: Convert the original set of constraints $\mathrm{X}^{\prime}$ of problem (CHMOILP) into the equivalent set of constraints $\mathrm{X}^{\square}$.

Step 3: Formulate the deterministic multiobjective integer linear problem (MOILP) corresponding to the problem (CHMOILP).

Step 4: Formulate the integer linear problem with a single-objective function $\mathrm{P}_{\mathrm{s}}(\varepsilon)$.

Step 5: Solve k-individual integer linear problem $P_{r},(r$ $=1,2, \ldots, \mathrm{k})$ where $\mathrm{P}_{\mathrm{r}}: \max \mathrm{f}_{\mathrm{r}}(\mathrm{x}),(\mathrm{r}=1,2, \ldots, \mathrm{k})$, subject to $\mathrm{x} \in \mathrm{X}^{\prime}$, to find the optimal integer solutions of the k-objectives.

Step 6: Construct the payoff table and determine $n_{r}$, $\mathrm{M}_{\mathrm{r}}$ (the smallest and the largest numbers in the $\mathrm{r}^{\text {th }}$ column in the payoff table).

Step 7: Determine the $\varepsilon_{\mathrm{i}}$ 's from the formula:

$\varepsilon_{\mathrm{r}}=\mathrm{n}_{\mathrm{r}}+\frac{\mathrm{t}}{\mathrm{N}-1}\left(\mathrm{M}_{\mathrm{r}}-\mathrm{n}_{\mathrm{r}}\right), \mathrm{r} \in \mathrm{K}-\{\mathrm{s}\}$

where $t$ is the number of all partitions of the interval $\left[\mathrm{n}_{\mathrm{r}}, \mathrm{M}_{\mathrm{r}}\right]$.

Step 8: Find the

$\mathfrak{I}=\left\{\varepsilon \in \mathrm{R}^{\mathrm{k}-1} \mid \mathrm{n}_{\mathrm{r}} \leq \varepsilon_{\mathrm{r}} \leq \mathrm{M}_{\mathrm{r}}, \mathrm{r} \in \mathrm{K}-\{\mathrm{s}\}\right\}$

set

Step 9: Choose $\varepsilon_{r}^{*} \in \mathfrak{I}$ and solve the integer linear problem $\mathrm{P}_{\mathrm{s}}\left(\varepsilon^{*}\right)$ using the branch-and-bound method $^{[9]}$ to find its optimal integer solution $\mathrm{X}^{*}$.

Step 10: Determine the set If $\mathrm{T}_{1}\left(\mathrm{x}^{*}\right)$ by utilizing the Kuhn-Tucker necessary optimality conditions $\left.{ }^{*}\right)$ corresponding to problem $\mathrm{P}_{\mathrm{s}}(\varepsilon)$.

Step 11: If $\mathrm{T}_{2}\left(\mathrm{x}^{*}\right)$ is a singleton, go to step 12 . Otherwise, go to step 13.
Step 12: Define

$\mathrm{T}_{2}\left(\mathrm{x}^{*}\right)=\left\{\varepsilon \in \mathrm{R}^{\mathrm{k}-1} \mid \varepsilon_{\mathrm{r}}^{*}-\Delta \leq \varepsilon_{\mathrm{r}}^{*} \leq \mathrm{M}_{\mathrm{r}}, \mathrm{r} \in \mathrm{K}-\{\mathrm{s}\}\right\}$, wher

e $\Delta$ is any small prespecfied positive real number.

Step 13: Determine $\mathfrak{I}-\mathrm{T}_{2}\left(\mathrm{x}^{*}\right)$. If $\mathfrak{I}-\mathrm{T}_{2}\left(\mathrm{x}^{*}\right)=\phi$, stop. Otherwise, go to step 14 .

Step 14: Choose another $\varepsilon_{\mathrm{r}}=\bar{\varepsilon}_{\mathrm{r}} \in \mathfrak{I}-\mathrm{T}_{2}\left(\mathrm{x}^{*}\right)$ and go to step 9.

The above algorithm terminates when the range of $\mathfrak{I}$ is fully exhausted. Then, the stability set of the first kind $\mathrm{S}\left(\mathrm{x}^{*}\right)$ is given as:

$S\left(x^{*}\right)=\bigcup_{i=1}^{k-1} T_{i}\left(x^{*}\right)$.

\section{AN ILLUSTRATIVE EXAMPLE}

Here, we provide a numerical example to clarify the developmental theory and the proposed algorithm. The problem under consideration is the following bicriterion integer linear programming problem involving random parameters in the right-hand side of the constraints (CHBILP).

$\left(\right.$ CHBILP): $\max F(x)=\left[f_{1}(x), f_{2}(x)\right]$,

Subject to

$\mathrm{P}\left\{\mathrm{x}_{1}+\mathrm{x}_{2} \leq \mathrm{b}_{1}\right\} \geq 0.90, \mathrm{P}\left\{-\mathrm{x}_{1}+\mathrm{x}_{2} \leq \mathrm{b}_{2}\right\} \geq 0.95, \mathrm{P}\left\{3 \mathrm{x}_{1}+\mathrm{x}_{2}\right.$ $\left.\leq \mathrm{b}_{3}\right\} \geq 0.90, \mathrm{x}_{1}, \mathrm{x}_{2} \geq 0$ and integers.

Where

$\mathrm{f}_{1}(\mathrm{x})=2 \mathrm{x}_{1}+\mathrm{x}_{2}, \mathrm{f}_{2}(\mathrm{x})=\mathrm{x}_{1}+2 \mathrm{x}_{2}$.

Suppose that $b_{i},(i=1,2,3)$ is normally distributed random parameters with the following means and variances.

$\mathrm{E}\left\{\mathrm{b}_{1}\right\}=1, \mathrm{E}\left\{\mathrm{b}_{2}\right\}=3, \mathrm{E}\left\{\mathrm{b}_{3}\right\}=9, \operatorname{Var}\left\{\mathrm{b}_{1}\right\}=25$, $\operatorname{Var}\left\{b_{2}\right\}=4, \operatorname{Var}\left\{b_{3}\right\}=4$,

From standard normal tables, we have:

$\mathrm{K}_{\alpha_{1}=} \mathrm{K}_{\alpha_{3}=} \mathrm{K}_{0.90} \cong 1.285, \mathrm{~K}_{\alpha_{2}=} \mathrm{K}_{0.95} \cong 1.645$

For the first constraint, the equivalent deterministic constraint is given by:

$\mathrm{x}_{1}+\mathrm{x}_{2} \leq \mathrm{C}_{1}=\mathrm{E}\left\{\mathrm{b}_{1}\right\}+K_{\alpha_{1}} \sqrt{\operatorname{Var}\left\{b_{1}\right\}}=1+1.285(5)=$ 7.425

For the second constraint: $-\mathrm{x}_{1}+\mathrm{x}_{2} \leq \mathrm{C}_{2}=\mathrm{E}\left\{\mathrm{b}_{2}\right\}+$ $K_{\alpha_{2}} \sqrt{\operatorname{Var}\left\{b_{2}\right\}}=3+1.645(2)=6.29$

For the third constraint: $3 \mathrm{x}_{1}+\mathrm{x}_{2} \leq \mathrm{C}_{3}=\mathrm{E}\left\{\mathrm{b}_{3}\right\}+$ $K_{\alpha_{3}} \sqrt{\operatorname{Var}\left\{b_{3}\right\}}=9+1.285(2)=11.57$

Therefore, the problem (CHBILP) can be understood as the corresponding deterministic bicriterion integer linear programming problem in the form:

(BILP): $\max \left[\mathrm{f}_{1}(\mathrm{x})=2 \mathrm{x}_{1}+\mathrm{x}_{2}, \mathrm{f}_{2}(\mathrm{x})=\mathrm{x}_{1}+2 \mathrm{x}_{2}\right]$, subject to $\mathrm{x}_{1}+\mathrm{x}_{2} \leq 7.425,-\mathrm{x}_{1}+\mathrm{x}_{2} \leq 6.29,3 \mathrm{x}_{1}+\mathrm{x}_{2} \leq 11.57, \mathrm{x}_{1}$, $\mathrm{x}_{2} \geq 0$ and integers.

Using the $\varepsilon$-constraint method ${ }^{[8]}$, then problem (BILP) above with a single-objective function becomes: $\mathrm{P}_{1}(\varepsilon)$ : $\max \mathrm{f}_{1}(\mathrm{x})=2 \mathrm{x}_{1}+\mathrm{x}_{2}$, subject to $\mathrm{x}_{1}+2 \mathrm{x}_{2} \geq \varepsilon_{2}, \mathrm{x}_{1}+$ $\mathrm{x}_{2} \leq 7.425, \quad-\mathrm{x}_{1}+\mathrm{x}_{2} \leq 6.29,3 \mathrm{x}_{1}+\mathrm{x}_{2} \leq 11.57, \mathrm{x}_{1}, \mathrm{x}_{2}$ $\geq 0$ and integers. 
It can be shown easily that $12.7775 \leq \varepsilon_{2} \leq 14.2825$.

Problem $P_{1}(\varepsilon)$ can be solved at $\varepsilon_{2}=\varepsilon_{2}{ }^{*}=13$ using the branch-and-bound method ${ }^{[9]}$ and its optimal integer solution is found $\left(\mathrm{x}_{1}{ }^{*}, \mathrm{x}_{2}{ }^{*}\right)=(1,6)$.

Furthermore, problem $P_{1}(\varepsilon)$ can be rewritten in the following parameters form as: $\mathrm{P}_{1}{ }^{\prime}(\varepsilon)$ : $\max \mathrm{f}_{1}(\mathrm{x})=2 \mathrm{x}_{1}+$ $\mathrm{x}_{2}$,

Subject to

$\mathrm{x}_{1}+2 \mathrm{x}_{2} \geq \varepsilon_{2}, \mathrm{x}_{1}+\mathrm{x}_{2} \leq 7.425,-\mathrm{x}_{1}+\mathrm{x}_{2} \leq 6.29,3 \mathrm{x}_{1}+\mathrm{x}_{2} \leq$ $11.57,0 \leq \mathrm{x}_{1} \leq 1,0 \leq \mathrm{x}_{2} \leq 6$

Therefore, the Kuhn-Tucker necessary optimality conditions corresponding to problem $\mathrm{P}_{1}{ }^{\prime}(\varepsilon)$ will take the form:

$$
\begin{array}{r}
2+\mu_{1}-\delta_{1}+\delta_{2}-3 \delta_{3}-\mathrm{u}_{1}=0, \\
1+2 \mu_{1}-\delta_{1}-\delta_{2}-\delta_{3}-\mathrm{u}_{2}=0, \\
\mathrm{x}_{1}+2 \mathrm{x}_{2} \geq \varepsilon_{2}, \\
\mathrm{x}_{1}+\mathrm{x}_{2} \leq 7.425, \\
-\mathrm{x}_{1}+\mathrm{x}_{2} \leq 6.29, \\
3 \mathrm{x}_{1}+\mathrm{x}_{2} \leq 11.57, \\
0 \leq \mathrm{x}_{1} \leq 1, \\
0 \leq \mathrm{x}_{2} \leq 6, \\
\mu_{1}\left(-\mathrm{x}_{1}-2 \mathrm{x}_{2}+\varepsilon_{2}\right)=0, \\
\delta_{1}\left(\mathrm{x}_{1}+\mathrm{x}_{2}-7.425\right)=0, \\
\delta_{2}\left(-\mathrm{x}_{1}+\mathrm{x}_{2}-6.29\right)=0, \\
\delta_{3}\left(3 \mathrm{x}_{1}+\mathrm{x}_{2}-11.57\right)=0, \\
\mathrm{u}_{1}\left(\mathrm{x}_{1}-1\right)=0, \\
\mathrm{u}_{2}\left(\mathrm{x}_{2}-6\right)=0, \\
\mu_{1}, \delta_{1}, \delta_{2}, \delta_{3}, \mathrm{u}_{1}, \mathrm{u}_{2} \geq 0
\end{array}
$$

Where all the above expressions of the system (\#) are evaluated at the optimal integer solution

$\left(\mathrm{x}_{1}{ }^{*}, \mathrm{x}_{2}{ }^{*}\right)=(1,6)$. In addition, it can be shown that:

$\delta_{1}=\delta_{2}=\delta_{3}=0, u_{1}, u_{2}>0, \mu_{1} \geq 0$.

Therefore, the set $T_{1}(1,6)$ is given by:

$\mathrm{T}_{1}(1,6)=\left\{\varepsilon \in \mathrm{R} \mid 12.7775 \leq \varepsilon_{2} \leq 13\right\}$.

A systematic variation of $\varepsilon_{2} \in R$ and $12.775 \leq \varepsilon_{2} \leq$ 13 will yield another stability set $T_{2}(1,6)$.

\section{CONCLUSION}

The general purpose of this study was to investigate the stability of the efficient solution for chanceconstrained multiobjective integer linear programming problem. A parametric study has been carried out on the problem under consideration, where some basic stability notions have been defined and characterized for the formulated problem.

Many aspects and general questions remain to be studied and explored in the field of multi objective integer optimization problems under randomness. This study is an attempt to establish underlying results which hopefully will help others to answer some or all of these questions.

There are however several unsolved problems, in our opinion, to be studied in the future. Some of these problems are:
* An algorithm is required for solving multiobjective integer linear programming problems involving random parameters in the left-hand side of the constraints

* An algorithm is needed for treating a large-scale multiobjective integer linear nonlinear programming problems under randomness,

* An algorithm should be handled for solving integer linear and integer nonlinear goal programs involving random parameters.

\section{REFERENCES}

1. Stochastic Programming Web Site, 2002. http:// Stoprog.org, Current as of July 2002.

2. El-Banna, A.Z. and E.A. Youness, 1993. On some basic notions of stochastic multiobjective problems with random parameters in the constraints. Microelectron. Reliab., 33: 1981-1986.

3. Guddat, J., F. Vasquez, K. Tammer and K. Wendler, 1985. Multi objective and Stochastic Optimization Based on Parametric Optimization,. Akademie-Verlage, Berlin.

4. Osman, M.S.A. and O.M. Saad, 1994. On the solution of chance-constrained multiobjective linear programming problems with a parametric study. Proc. First Intl. Conf. Operations Research and its Applications. Higher Technological Institute, Ramadan Tenth. City, Egypt.

5. Vogel, S., 1992. On stability in multiobjective programming-a stochastic approach. Math. Program., 60: 91-119.

6. Osama, Ez-Eldin, 2000. On stochastic multiobjective integer linear programming problems. M.SC. Thesis. Helwan University, Cairo, Egypt.

7. Seppälä, Y., 1988. On accurate linear approximations for chance-constrained programming. J. Opl. Res. Soc., 39: 693-694.

8. Chankong, V. and Y.Y. Haimes, 1983. Multi objective decision-making: theory and methodology. (North Holland Series in System Science and Engineering).

9. Taha, H.A., 1975. Integer Programming: Theory, Applications and Computations. Academic Press, New York.

10. Osman, M.S.A., 1977. Qualitative analysis of basic notions in parametric convex programming $\mathrm{i}$ (parameters in the constraints). Appl. Math. CSSR Akad. Ved. Prague, 22: 318-332.

11. Osman, M.S.A., 1977. Qualitative analysis of basic notions in parametric convex programming II (parameters in the objective function). Appl. Math. CSSR Akad. Ved. Prague, 22: 333-348.

12. Balinski, M., 1961. An algorithm for finding all vertices of convex polyhedral sets. SIAM J., 9: 72-88. 